\title{
Rheumatology and Orthopedic Medicine
}

\section{Research Article}

\section{An orthopaedic elective for pediatric residents}

\author{
Brian Piazza ${ }^{1}$, Bjorn Nilson ${ }^{2}$, Robert Wells ${ }^{2}$ and William Hennrikus ${ }^{*}$ \\ ${ }^{1}$ Department of Orthopaedics, Penn State College of Medicine, 30 Hope Drive Hershey, USA \\ ${ }^{2}$ Department of Pediatrics, Valley Children's Hospital, 9300 Valley Children's Place Madera, USA
}

\begin{abstract}
Background: Musculoskeletal complaints account for about $15 \%$ of primary care visits. However, orthopaedic education is often lacking in both medical school and pediatric residency. Primary care physicians often report low confidence in evaluation of orthopaedic diagnoses. The literature supports the need for increased musculoskeletal education in both residency and medical school.
\end{abstract}

Objective: The aim of this study is to report the education and confidence outcomes for a structured one orthopaedic elective for pediatric residents.

Methods: Twelve male and 25 females ( $\mathrm{N}=37$ ) pediatric residents were enrolled in a prospective study designed to improve musculoskeletal knowledge and confidence when managing orthopaedic problems. A 50-question pre-test and a 50-question confidence questionnaire was taken at the beginning and end of the one month elective.

Results: The average pre-test score was $54 \%$ correct vs $89 \%$ correct on the post-test $(\mathrm{P}<.001)$. The confidence of residents to perform a physical exam, accurately diagnose and treat common orthopaedic conditions improved from an average of $4 / 10$ to $9 / 10(\mathrm{P}<.001)$

Conclusions: Pediatric residents can develop a better understanding of the evaluation and treatment of musculoskeletal problems and therefore be more confident in addressing orthopaedic diagnoses in their clinic after participating in a formal one month orthopaedic elective rotation.

\section{Introduction}

Approximately $10 \%-30 \%$ of patients who are seen by a primary care physician are seeking care due to a musculoskeletal complaint [1-4]. De Inocencio reports that $>6 \%$ or pediatric clinic visits are musculoskeletal pain with nearly $30 \%$ attributable to trauma or overuse $e^{4}$. Schwend and Geiger reported that approximately one third of medical problems in children are related to the musculoskeletal system [5]. Medical school and primary care residency musculoskeletal curriculum is often minimal [6-11]. Graduating pediatric residents have ranked their level of confidence lowest in evaluating musculoskeletal problems and their management compared with other areas of pediatric medicine. In addition, graduating residents believed residency training should place more emphasis on musculoskeletal medicine [12]. Jandial et al reported that $74 \%$ of physicians, whom routinely evaluate pediatric patients, have low confidence in pediatric musculoskeletal assessment [13].

These deficiencies in orthopaedic knowledge and confidence may jeopardize patient care. For example, Reeder et al reported that $42 \%$ of referrals to his pediatric orthopaedic clinic did not meet the American Academy of Pediatrics guidelines for referral [14,15]. Similarly, Sielatycki reported in a study examining referrals for children with intoeing that none of 143 referred patients needed orthopaedic care and their diagnoses were all normal variation of development that could be cared for by a pediatrician [16].

Alternatively, some musculoskeletal issues are under-recognized and referred late, such as slipped capital femoral epiphysis (SCFE) which requires urgent treatment. For example, Schur et al reported that of 481 patients diagnosed with slipped capital femoral epiphysis; time to diagnosis was delayed by a mean of 4 weeks if evaluated by a primary care physician and delayed 6 weeks if evaluated by an emergency department physician [17]. This delay in care for SCFE is similar to the data that Kocher reported in 2004 [18].

Integrated education and musculoskeletal rotations have been shown to increase physician's knowledge and confidence in treating musculoskeletal complaints $[6,19,20]$. However, there is minimal literature to support this finding in pediatric residents. The aim of this study is to report the education and confidence outcomes for pediatric residents enrolled in a structured one month elective in orthopaedics.

\section{Methods}

The study was approved by the hospital institutional review board (IRB). Thirty-seven pediatric residents were enrolled in a prospective study designed to evaluate pediatric resident's musculoskeletal fund of knowledge and the resident's confidence when managing patients with orthopaedic diagnoses. Each resident spent one month on the orthopaedic service under the supervision of the senior author (WH). On the first day of the service, the resident took a 50 -question pretest and a 50-question confidence questionnaire. The pre-test was graded and reviewed with the resident. The questionnaire rated the resident's confidence with a 10-point scale in physical exam, diagnosis, and treatment of multiple common orthopaedic problems. During

Correspondence to: William Hennrikus MD, Department of Orthopaedics, Penn State College of Medicine, 30 Hope Drive Hershey, PA 17033, USA, Tel: 717.531-7006, E-mail: Whennrikus@hmc.psu.edu

Key words: education, pediatric, orthopaedic, musculoskeletal

Received: January 05, 2017; Accepted: February 04, 2017; Published: February 07,2017 
the month, time was spent in the clinic, casting room, inpatient care, operating room and emergency room. The pediatric resident participating in weekly pediatric orthopaedic conferences and a monthly journal club.

A copy of Pediatric Orthopaedics in Primary Practices [21] and Pediatric Orthopaedics and Sports Injuries [22] was given to each resident and used as the primary resources for education. On the last day of the rotation, the resident took a similar 50 question post-test and the identical 50 question confidence questionnaire. The questionnaires and tests were then reviewed with the resident during an end of rotation feedback meeting.

\section{Results}

Thirty-seven residents participated in the study. Twelve residents were male and 25 were female. The average pre-test score was $54 \%$ correct vs $89 \%$ correct on the post-test $(\mathrm{P}<.001)$ (Figure 1$)$. The confidence of residents to perform a physical exam, accurately diagnose and treat common orthopaedic conditions improved from an average of $4 / 10$ to $9 / 10(\mathrm{P}<.001)$ (Figure 2$)$. Topics evaluated included: musculoskeletal physical examination, interpreting musculoskeletal radiographs, diagnosing a torus and supracondylar fractures, Perthes disease, developmental dysplasia of the hip (DDH), anterior cruciate ligament tear (ACL), SCFE, septic joint, treatment for torus fracture, nursemaids elbow, clavicle fractures, calcaneal apophysitis, Osgood Schlatter's disease, toxic synovitis and application of short arm splints and cast.

\section{Discussion}

The American Academy of Pediatrics report that $63 \%$ of pediatric residents will enter primary care [23]. Musculoskeletal pain ranks third as a reason for adolescent medical visits to the primary care physician [5]. In addition, musculoskeletal injuries are one of the most common reason for acute visits to the emergency department and primary care office [1-4]. Recognition of musculoskeletal diagnoses is very important in a pediatric clinical practice. Primary care physicians must know how to treat basic musculoskeletal problems, when to refer patients, and how to recognize orthopaedic emergencies. The foundation of this knowledge stems from appropriate medical school and residency training.

\section{Pre vs Post Rotation Test Scores}

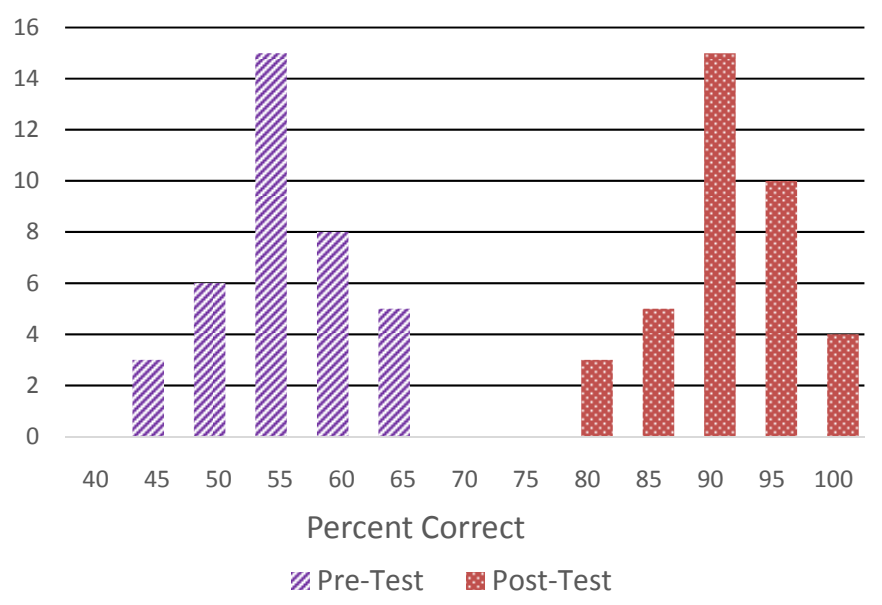

Figure 1. Pre-and post-rotation test scores.
Pre vs Post Rotation Confidence Scores

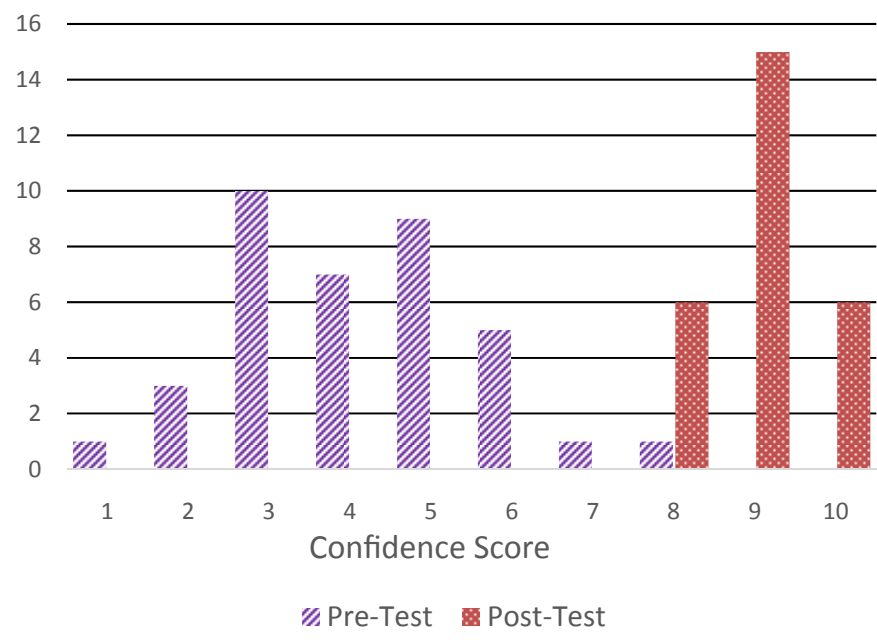

Figure 2. Pre-and post rotation confidence scores.

The literature supports a need for increased musculoskeletal education in medical school and primary care residencies. For example, Matzkin reported that primary care physicians lacked adequate musculoskeletal knowledge, but primary care physicians who had participated in a musculoskeletal rotation scored significantly better on a validated basic cognitive examination than those that did not [24]. The musculoskeletal rotation at our institution is a month long immersion with an educational focus on physical examination, treatment and the need for referral for musculoskeletal problems commonly seen in the primary care practice [15]. At the culmination of the rotation, the thirty-seven pediatric residents exhibited a better understanding of the evaluation and treatment of musculoskeletal problems and were found to be much more confident in addressing these problems.

\section{Conclusion}

The current study illustrates the effectiveness of educating pediatric residents in musculoskeletal medicine through a structured one month orthopaedic elective rotation. We feel this study is applicable to other institutions. A one month orthopaedic rotation for all pediatric residents will help to address this proven deficiency in musculoskeletal medical education. Given the breath of musculoskeletal problems evaluated by general pediatricians and the lack of education in both medical school and residency we support a required musculoskeletal rotation for pediatricians intending to go into general pediatrics as well as those that may specialize in a musculoskeletal related field.

\section{References}

1. Al-Nammari SS, Pengas I, Asopa V, Jawad A, Rafferty M, et al. (2015) The inadequacy of musculoskeletal knowledge in graduating medical students in the United Kingdom. J Bone Joint Surg Am 97: e36. [Crossref]

2. Pinney SJ, Regan WD (2001) Educating medical students about musculoskeletal problems. Are community needs reflected in the curricula of Canadian medical schools? J Bone Joint Surg Am 83: 1317-1320. [Crossref]

3. de Inocencio J (1998) Musculoskeletal pain in primary pediatric care: analysis of 1000 consecutive general pediatric clinic visits. Pediatrics 102: E63. [Crossref]

4. De Inocencio J (2004) Epidemiology of musculoskeletal pain in primary care. Arch Dis Child 89: 431-434. [Crossref]

5. Schwend RM, Geiger J (1998) Outpatient pediatric orthopedics. Common and important conditions. Pediatr Clin North Am 45: 943-971. [Crossref] 
6. Button JH, Bruel BM, Francisco GE (2007) Assessment of musculoskeletal examination skills: physiatry residents as evaluators and models. Am J Phys Med Rehabil 86: 926934. [Crossref]

7. Day CS, Bernstein J, Boyer MI (2012) Educating medical students in musculoskeletal surgery and medicine-how to get a course up and running at your institution: AOA critical issues. J Bone Joint Surg Am 94: e1761-1766. [Crossref]

8. Day CS, Yeh AC, Franko O, Ramirez M, Krupat E (2007) Musculoskeletal medicine: an assessment of the attitudes and knowledge of medical students at Harvard Medical School. Acad Med 82: 452-457. [Crossref]

9. Day CS, Ho P (2016) Progress of Medical School Musculoskeletal Education in the 21st Century. J Am Acad Orthop Surg 24: 762-768. [Crossref]

10. DiCaprio MR, Covey A, Bernstein J (2003) Curricular requirements for musculoskeletal medicine in American medical schools. J Bone Joint Surg Am 85-85A: 565-7. [Crossref]

11. Murnaghan JJ, Stauffer ES, Darosa DA, Folse JR (1995) Topics and skills in orthopaedics for the general practitioner. J Bone Joint Surg Am 77: 1692-1694. [Crossref]

12. Taras HL, Nader PR (1990) Ten years of graduates evaluate a pediatric residency program. Am J Dis Child 144: 1102-1105. [Crossref]

13. Jandial S, Myers A, Wise E, Foster HE (2009) Doctors likely to encounter children with musculoskeletal complaints have low confidence in their clinical skills. J Pediatr 154: 267-271. [Crossref]

14. Reeder BM, Lyne ED, Patel DR, Cucos DR (2004) Referral patterns to a pediatric orthopedic clinic: implications for education and practice. Pediatrics 113: e163-167. [Crossref]
15. Surgical Advisory Panel, American Academy of Pediatrics, Klein MD (2014) Referral to pediatric surgical specialists. Pediatrics 133: 350-356. [Crossref]

16. Sielatycki JA, Hennrikus WL, Swenson RD, Fanelli MG, Reighard CJ, et al. (2016) In-Toeing Is Often a Primary Care Orthopedic Condition. J Pediatr 177: 297-301. [Crossref]

17. Schur MD, Andras LM, Broom AM, Barrett KK, Bowman CA, et al. (2016) Continuing Delay in the Diagnosis of Slipped Capital Femoral Epiphysis. J Pediatr 177: 250-254. [Crossref]

18. Kocher MS, Bishop JA, Weed B, Hresko MT, Millis MB, et al. (2004) Delay in diagnosis of slipped capital femoral epiphysis. Pediatrics 113: e322-325. [Crossref]

19. Saleh K, Messner R, Axtell S, Harris I, Mahowald ML (2004) Development and evaluation of an integrated musculoskeletal disease course for medical students. $J$ Bone Joint Surg Am 86-86A: 1653-8. [Crossref]

20. Bilderback K, Eggerstedt J, Sadasivan KK, Seelig L, Wolf R, et al. (2008) Design and implementation of a system-based course in musculoskeletal medicine for medical students. J Bone Joint Surg Am 90: 2292-2300. [Crossref]

21. Pizzutillo P (1997) Pediatric orthopaedics in primary practice: Health Professions Division, McGraw-Hill

22. Pediatric Orthopaedics and Sports Injuries, 2nd Edition2010.

23. Research AAoPDo. Annual survey of graduating residents 2010.

24. Matzkin E, Smith EL, Freccero D, Richardson AB (2005) Adequacy of education in musculoskeletal medicine. J Bone Joint Surg Am 87: 310-314. [Crossref]

Copyright: @2017 Piazza B. This is an open-access article distributed under the terms of the Creative Commons Attribution License, which permits unrestricted use, distribution, and reproduction in any medium, provided the original author and source are credited. 